\title{
Effects of ischemic preconditioning and cilostazol on muscle ischemia-reperfusion injury in rats ${ }^{1}$
}

\author{
Carlos Alberto da Silva Frias Neto', Márcia Kiyomi Koike" ${ }^{\mathrm{II}}$, Karen Ruggeri Saad ${ }^{\mathrm{III}}$, Paulo Fernandes Saad ${ }^{\mathrm{III}}$, Edna Frasson de \\ Souza Montero ${ }^{\mathrm{IV}}$
}

DOI: http://dx.doi.org/10.1590/S0102-86502014001700004

${ }^{\mathrm{I}} \mathrm{MD}$, Associate professor, Medical School, Federal University of Maranhão (UFMA), Brazil. Conception, design, intellectual and scientific content of study. ${ }^{\text {II }}$ Ph.D, Department of Clinical Medicine, Faculty of Medicine of São Paulo University (FMUSP), Brazil. Interpretation of data, manuscript writing, statistical analysis critical revision.

III Associate Professor, Medical School, Federal University of Vale do São Francisco (UNIVASF), Brazil. Interpretation of data, manuscript writing and critical revision.

IV Associate Professor, Surgical Physiopathology Laboratory (LIM-62), Medical School, Faculty of Medicine of São Paulo University (FMUSP), Brazil and Affiliate Professor, Surgical technique division, Medical School, Federal University of São Paulo, Brazil. Conception, design, intellectual, scientific content of study, critical revision and final approval.

\begin{abstract}
PURPOSE: To evaluate effects of ischemic preconditioning and Cilostazol on muscle ischemia-reperfusion injury.

METHODS: Male Wistar rats were submitted to muscle ischemic and reperfusion injury (4h of the left common iliac artery occlusion followed by $1 \mathrm{~h}$ of reperfusion). Five experimental groups were constituted: Control group ( $n=4)$; Ischemia-Reperfusion (IR, $n=5)$; Ischemic preconditioning group (IP, $\mathrm{n}=6$ ); Ischemia-Reperfusion group treated with cilostazol ( $\mathrm{IRCi}, \mathrm{n}=6$ ) and Ischemic preconditioning group treated with cilostazol (IPCi, $\mathrm{n}=6$ ). At the end, left gracile muscle was removed and embedded in paraffin. Histopathology, neutrophil infiltration, myocyte necrosis and edema were analyzed.

RESULTS: When compared with the control group, IR group showed increased neutrophil infiltration, severe necrosis and edema. There was significant difference between myocytes necrosis of IR group and IP group. There was no difference between the histopathological changes between IP, IRCi and IPCi groups.

CONCLUSIONS: The model of IR caused severe muscle injury in the rat hind limb and ischemic preconditioning has a protective effect, reducing myocyte necrosis, however, treatment with cilostazol and also the association between cilostazol and preconditioning has no protective effect on the skeletal muscle subjected to ischemia and reperfusion injury.
\end{abstract}

Key words: Ischemic preconditioning. Muscle injury. Cilostazol. Rats. 


\section{Introduction}

Despite the development of reconstructive surgery techniques have led the possibility to preservation of members function affected by severe trauma or resection of malignant musculoskeletal tumors, ischemia and reperfusion (IR) injury remain as the major cause of failure of transfer of tissues, leading to extensive surgical revisions or amputation of the extremity ${ }^{1,2}$. IR injury happens when, during ischemia, blood flow interruption creates local lesions in proportion to oxygen and nutriment privation time, urging reperfusion to be performed as soon as possible. However, reperfusion itself induces more cellular alterations, likely through mitochondrial dysfunction, increased reactive oxygen species production, and inflammation ${ }^{3,4,5}$.

Several methods, such as thrombolytic agents, hyperbaric oxygen treatment, and anti-inflammatory agents have been tested to prevent or lessen the harmful effects of IR injury ${ }^{6}$. It has been shown that Ischemic Preconditioning (IP) confers natural tissue protection to prolonged ischemic stress, involving multiple mediators of ischemic damage such as adenosine, norepinephrine, bradykinin, and unidentified opioids ${ }^{7}$. IP in skeletal muscle has showed a protective effect in vascular reperfusion, cellular membrane structure and function, muscle preservation, decreasing inflammatory infiltrate and vascular stasis ${ }^{8-12}$.

On the other hand, cilostazol is a potent and selective inhibitor of phosphodiesterase III. This enzyme increases cyclic adenosine 3 ', 5'-monophosphate (c AMP) in thrombocytes and smooth muscle cells decreasing intracellular calcium with consequent relaxation and vasodilation. AMPc, in turn, is a regulator of immune and inflammatory responses ${ }^{13}$.

The protective action of cilostazol in IR injury has been demonstrated in the central nervous system, ${ }^{14,15}$ renal tissue ${ }^{6}$, heart ${ }^{17}$ and in chronic arterial disease ${ }^{16}$. But the protective role of this drug in acute IR injury of skeletal muscle is not yet established. Studies have indicated the protective role of this drug in skeletal muscle, through the effect on endothelium dependent vascular reactivity ${ }^{19}$, however, no decrease in muscle damage as a biomarker of serum myoglobin muscle and other histopathological changes and apoptosis using cilostazol was observed in IR muscle models ${ }^{20.21}$. The effects of IP associated with cilostazol treatment in muscle ischemia-reperfusion injury did not studied yet. The aim of this study was evaluate the effects of IP associated with cilostazol in experimental model of muscle ischemia-reperfusion injury.

\section{Methods}

All animals were handled according to the ethical principles of laboratory animal care according to law 11.794, October 8, 2008, which governs the ethical use of animals for experimentation and followed the guidelines by the Research Ethics Committee of the UNIFESP.

Adult male Wistar rats (Rattus norvegicus albinus), aged between 90 and $120 \mathrm{~d}$ and weighing between 250 and 300 $\mathrm{g}$, were used. The animals were kept six days for observation and adaptation, in appropriate cages (40 X 30 X $25 \mathrm{~cm})$, with a maximum of five animals per cage, under controlled conditions for light, temperature, and daily hygiene. They received water and balanced chow ad libitum.

\section{Experimental groups}

The animals were randomly distributed into the following groups: Control group ( $\mathrm{CG}, \mathrm{n}=4)$ : These animals were submitted to the anesthesia and the surgical procedure, without IR injury induction; Ischemia-Reperfusion group (IR, $n=5)$ : These animals were submitted to a prolonged ischemia (4hs) and reperfusion (1h); Ischemic preconditioning group (IP, $n=6$ ): These animals were submitted to a PCI (10x10 minutes) before prolonged ischemia (4hs) and reperfusion (1h); Ischemia-Reperfusion group treated with cilostazol (IRCi, $\mathrm{n}=6$ ): These animals received $30 \mathrm{mg} / \mathrm{kg}$ of cilostazol before prolonged ischemia (4hs) and reperfusion (1h); Ischemic preconditioning group treated with cilostazol (IPCi, $\mathrm{n}=6)$ : These animals received $30 \mathrm{mg} / \mathrm{kg}$ of cilostazol and PCI $(10 \mathrm{x}$ 10 minutes) before prolonged ischemia (4hs) and reperfusion (1h).

\section{Induction of IR injury of skeletal muscle}

The animals were anesthetized with a combination of ketamine $(50 \mathrm{mg} / \mathrm{kg})$ and xylazine $(15 \mathrm{mg} / \mathrm{kg})$ via intramuscularly injection. The animals were considered anesthetized when they were unresponsive to mechanical stimuli, being unable to withdraw the hind limb after pain stimulus and also presented absence of palpebral reflexes. Additional doses of anesthesia (half of the initial dose) were administered approximately every $50 \mathrm{~min}$. The animals were also kept well ventilated at room temperature. The animals were placed on a constantly heated plate $\left(37^{\circ} \mathrm{C}\right)$ in supine position with hind limbs immobilized and adhesive tape across the chest. Trichotomy was performed on the abdomen region with a razor blade followed by antisepsis of the operative area with iodine polyvinylpyrrolidone tincture.

Using a no. 11 scalpel blade, a skin incision was made, with dissection and isolation of the left common iliac artery. This artery was clamped during 4 hours and then, the clamp was removed. 
The animals were observed for more 1 hour, at which time they were euthanized by lethal dose of anesthetic.

\section{Cilostazol and Ischemic preconditioning}

Cilostazol were dissolved in dimethyl sulphoxide and injected intraperitoneally $(30 \mathrm{mg} / \mathrm{kg}) 20$ minutes before of prolonged ischemia.

The Ischemic preconditioning consisted of 10 minutes occlusion of the left common iliac artery occlusion followed by 10 minutes of reperfusion, before prolonged ischemia.

\section{Collecting gracile muscle and histopathology}

After euthanasia, left inferior gracile muscle was excised, fixed in formalin solution, embedded in paraffin. Five micrometer sections were stained with hematoxylin-eosin (HE) and Neutrophil infiltration, muscular edema and signs of myocyte necrosis were evaluated under $100 \mathrm{x}$ of magnification and blinded manner by score method: absent (0), rare (1), moderate (2) and severe (3).

There were considered signs of myocyte necrosis: cellular vacuolization, band contraction and/or cellular destruction.

\section{Statistical analysis}

The data were analyzed using the SigmaStat statistical program, version 3.1 (Systat Software, SanJose, CA). The groups were compared by Kruskal-Wallis 1-way analysis of variance on ranks, after testing for normality and variance equality, and complemented by post hoc test (Dunn's test). The groups were also compared in pairs using the Mann Whitney test. Data were expressed median (25\%-75\%). Difference was considered statistically significant when $\mathrm{P}<0.05$.

\section{Results}

In table 1 are depict histological evaluation and in Figure 1 is depict representative photomicrographs.

TABLE 1. Qualitative histological evaluation of muscle edema, myocite necrosis and neutrophil infiltration of gracile muscle of rats submitted to ischemia-reperfusion injury.

\begin{tabular}{lccccc}
\hline & $\begin{array}{c}\mathrm{CG} \\
(\mathrm{n}=4)\end{array}$ & $\begin{array}{c}\text { IR } \\
(\mathrm{n}=5)\end{array}$ & $\begin{array}{c}\text { IRCi } \\
(\mathrm{n}=6)\end{array}$ & $\begin{array}{c}\text { IP } \\
(\mathrm{n}=6)\end{array}$ & $\begin{array}{c}\text { IPCi } \\
(\mathrm{n}=6)\end{array}$ \\
\hline Edema & $0.00 \pm 0.00$ & $2.00 \pm 0.45$ & $1.83 \pm 0.17$ & $1.33 \pm 0.21$ & $1.50 \pm 0.22$ \\
& $0.0(0.0-0.0)$ & $2.0(1.0-3.0)$ & $2.0(2.0-2.0)$ & $1.0(1.0-2.0)$ & $1.5(1.0-2.0)$ \\
Myocyte & $0.00 \pm 0.00$ & $1.53 \pm 1.36$ & $0.33 \pm 0.51$ & $0.22 \pm 0.40$ & $0.67 \pm 0.67$ \\
necrosis & $0.0(0.0-0.0)$ & $1.0(0.3-3.0)$ & $0.0(0.0-1.0)$ & $0.0(0.0-0.33)$ & $0.67(0.0-1.0)$ \\
Neutrophyl & $0.00 \pm 0.00$ & $1.80 \pm 0.49$ & $0.83 \pm 0.17$ & $0.83 \pm 0.17$ & $0.83 \pm 0.17$ \\
infiltration & $0.0(0.0-0.0)$ & $1.0(1.0-3.0)$ & $1.0(1.0-1.0)$ & $1.0(1.0-1.0)$ & $1.0(1.0-1.0)$ \\
\hline
\end{tabular}

IR: Ischemia-reperfusion injury; Ci: cilostazol; IP: ischemic preconditioning. Values are presented on
mean \pm standart error followed to median $(25 \%-75 \%)$.

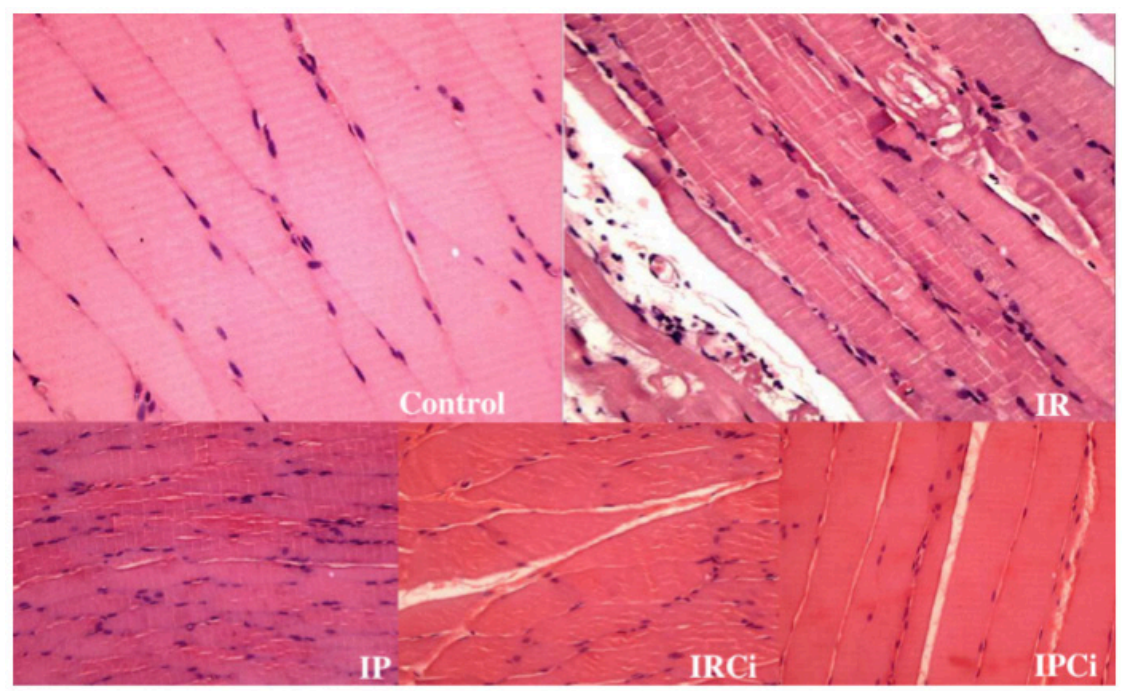

FIGURE 1 - Photomicrographs depicting gracile muscle from rats submitted o ischemia-reperfusion injury (IR) with or without cilostazol (Ci) treatment and/or ischemic preconditioning (IP) compared to control rats. Right top panels show intense inflammatory cell infiltration, edema and myocyte necrosis from IR group in contrast with normal tissue from Control group. Bottom panels show reduction of inflammation, necrosis and/or edema in groups submitted to IP or treated by cilostazol. HE, 100X 
In the table 2, p-values obtained by comparing the experimental groups and the IR group is depicted. Prolonged ischemia of the left hind limb and reperfusion promotes intense neutrophil infiltration, necrosis and edema within gracile muscle. The IP group appeared to reduce myocyte necrosis in muscle tissue, but cilostazol or the association between preconditioning and cilostazol did not protect skeletal muscle from IR injury.

TABLE 2. Comparison between the experimental groups and the IR group for edema, myocyte necrosis and neutrophil infiltration.

\begin{tabular}{|c|c|c|c|c|c|}
\hline & & $\begin{array}{c}\mathrm{CG} \\
(\mathrm{n}=4)\end{array}$ & $\begin{array}{l}\text { IRCi } \\
(n=6)\end{array}$ & $\begin{array}{c}\mathrm{IP} \\
(\mathrm{n}=6)\end{array}$ & $\begin{array}{l}\text { IPCi } \\
(n=6)\end{array}$ \\
\hline & & \multicolumn{4}{|c|}{$p$ value } \\
\hline Edema & IR & $0,01 *$ & 0,79 & 0,42 & 0,9 \\
\hline $\begin{array}{l}\text { Myocyte } \\
\text { necrosis }\end{array}$ & $(n=5)$ & $0,01 *$ & 0,08 & $0,03 *$ & 0,33 \\
\hline $\begin{array}{l}\text { Neutrophyl } \\
\text { infiltration }\end{array}$ & & $0,01 *$ & 0,18 & 0,33 & 0,18 \\
\hline
\end{tabular}

IR: Ischemia-reperfusion injury; Ci: cilostazol; IP: ischemic preconditioning. * Statistically significant difference.

There was no difference between histopathological changes of IPCi and IP group as there was no difference between the histopathological changes between IPCi and IRCi groups.

\section{Discussion}

Ischemia means absence of blood flow and consequent reduction or absence of oxygen offer and substrates to the tissue besides excess of metabolites in human being. Acute ischemia can cause, if there is no recovery of blood flow, from small areas of necrosis to member amputations. However, recovery of arterial flow after acute ischemia results, generally, in the morpho-functional restoration, but in some cases a complex post revascularization syndrome appears, causing some times loss of members or life ${ }^{7}$.

One of the first signs that occur after reperfusion is the interstitial edema, caused by mechanical changes, such as increase in intracapillary pressure and in capillary permeability ${ }^{22}$. The ischemic process could promote important inflammatory reaction with neutrophil infiltration in the first 24 hours. Ischemic preconditioning promotes protection to ischemiareperfusion injury in muscle, showing the muscular fiber morphological preservation ${ }^{10}$. Other authors also observed that preconditioning had a protective effect by avoiding glycogen depletion in skeletal muscle in rats submitted to IR. In accordance with these studies, we also observed the protective effect of IP in this experimental model of IR Injury, especially with the reduction of myocyte necrosis.

Previously studies suggest that cilostazol could have a protective effect by perfusion increasing in ischemic areas and anti-apoptotic properties ${ }^{23,24}$. In addition, other studies have observed that cilostazol has a protective effect against ischemic injury in animal models, when observed in other organs ${ }^{25,26}$.

Francischetti et al. ${ }^{27}$ demonstrated that cilostazol reduces oxidative stress in rats subjected to $45 \mathrm{~min}$ of spinal cord ischemia by aortic clamping and reperfusion period of 48 hours. The biochemical and histopathological examination of animals treated with a dose of cilostazol $20 \mathrm{mg} / \mathrm{kg}$ orally for three days before spinal cord ischemia, demonstrated a reduction in neurological damage.

However, in this study, histopathological changes due to ischemia and reperfusion in animals treated with cilostazol in striated muscle were observed at a lower intensity, but without statistical difference when compared with the IR group animals. These results are consistent with the study of Moreira Neto et al. ${ }^{28}$ who found no protective effects of cilostazol in IR injury of skeletal muscle in similar experimental models with a reperfusion periods of 2 hours and 6 hours.

Cilostazol treatment alone or in combination with IP showed no significant effect on muscle injury protection in IR and suggests that more experimental studies are required to elucidate the role of these strategies in the treatment of muscle injury IR.

\section{Conclusion}

The model of IR caused severe muscle injury in the rat hind limb and ischemic preconditioning has a protective effect, reducing myocyte necrosis, however, despite signs that treatment with cilostazol and also the association between cilostazol and preconditioning could have a protective effect on this injury, this was not observed in this study.

\section{References}

1. Siemionow $\mathrm{M}$, Arslan E. Ischemia/reperfusion injury: a review in relation to free tissue transfers. Microsurgery. Sept;24(6):468-75. Review. PubMed PMID:15378577.

2. van den Heuvel MG, Buurman WA, Bast A, van der Hulst RR. Review: ischaemia-reperfusion injury in flap surgery. J Plast Reconstr Aesthet Surg. 2009 Jun;62(6):721-6. doi: 10.1016/j. bjps.2009.01.060. PubMed PMID: 19299216.

3. Pipinos II, Judge AR, Zhu Z, Selsby JT, Swanson SA, Johanning JM, Baxter BT, Lynch TG, Dodd SL. Mitochondrial defects and oxidative damage in patients with peripheral arterial disease. Free 
Radic Biol Med. 2006 Jul;41(2):262-9. PubMed PMID: 16814106.

4. Thaveau F, Zoll J, Rouyer O, Chafke N, Kretz JG, Piquard F, Geny B. Ischemic preconditioning specifically restores complexes I and II activities of the mitochondrial respiratory chain in ischemic skeletal muscle. J Vasc Surg. 2007 Sep;46(3):541-7. PubMed PMID: 17826242.

5. Blaisdell FW. The pathophysiology of skeletal muscle ischemia and the reperfusion syndrome: a review. Cardiovasc Surg. 2002 Dec;10(6):620-30. PubMed PMID: 12453699.

6. Armstrong DM, Armstrong Ada C, Figueiredo RC, Florentino JE, Saad PF, Fox-Talbot K, Halushka MK, Berkowitz DE, Taha MO, Fagundes DJ. Sildenafil citrate protects skeletal muscle of ischemiareperfusion injury: immunohistochemical study in rat model. Acta Cir Bras. 2013 Apr;28(4):282-7. PubMed PMID: 23568236.

7. Przyklenk K and Kloner RA. Ischemic preconditioning: exploring the paradox. Prog Cardiovasc Dis. 1998 May-Jun;40(6):517-47. PubMed PMID: 9647608.

8. Webster RS, Montero EFS, Fagundes DJ, Zettler CG, Coiro J. The role of ischemic preconditioning at the gracilis muscle of rats in the early phase of reperfusion injury. Acta Cir Bras. 2006 MarApr;21(2):80-6. PubMed PMID:16583059.

9. Attkiss KJ, Suski M, Hunt TK, Buncke HJ. Ischemic preconditioning of skeletal muscle improves tissue oxygenation during reperfusion. J Reconstr Microsurg. 1999 Apr;15(3):223-8. PubMed PMID: 10226958.

10. Pasupathy S; Homer-Vanniasinkam S. Surgical implications of ischemic preconditioning. Arch Surg. 2005 Apr;140(4):405-9. PubMed PMID: 15837893.

11. Zhang F, Oswald T, Holt J, Gerzenshtein J, Lei MP, Lineaweaver WC. Regulation of inducible nitric oxide synthase in ischemic preconditioning of muscle flap in a rat model. Ann Plast Surg. 2004 Jun;52(6):609-13. PubMed PMID: 15166998.

12. Gürke L, Mattei A, Chaloupka K, Marx A, Sutter PM, Stierli P, Harder F, Heberer M. Mechanisms of ischemic preconditioning in skeletal muscle. J Surg Res. 2000 Nov;94(1):18-27. PubMed PMID: 11038298 .

13. Rowlands TE, Donnelly R. Medical therapy for intermittent claudication. Eur J Vasc Endovasc Surg. 2007 Sep;34(3):314-21. PubMed PMID:17532651.

14. Sahin MA, Onan B, Guler A, Oztas E, Uysal B, Arslan S, Demirkilic U, Tatar H. Cilostazol, a type III phosphodiesterase inhibitor, reduces ischemia/reperfusion-induced spinal cord injury. Heart Surg Forum. 2011 Jun;14(3):E171-7. doi: 10.1532/HSF98.20101126. PubMed PMID: 21676683.

15. Ishiguro $M$, Mishiro K, Fujiwara $Y$, Chen H, Izuta H, Tsuruma K, Shimazawa M, Yoshimura S, Satoh M, Iwama T, Hara H. Phosphodiesterase-III inhibitor prevents hemorrhagic transformation induced by focal cerebral ischemia in mice treated with tPA. PLoS One. 2010 Dec;5(12):e15178. doi: 10.1371/journal.pone.0015178. PubMed PMID: 21151895; PubMed Central PMCID: PMC2997776.

16. Gokce M, Yuzbasioglu MF, Bulbuloglu E, Oksuz H, Yormaz S, Altınoren O, Kutlucan M, Coskuner I, Silay E, Kale IT. Cilostazol and diltiazem attenuate cyclosporine-induced nephrotoxicity in rats. Transplant Proc. 2012 Jul-Aug;44(6):1738-42. doi: 10.1016/j. transproceed.2012.04.025. PubMed PMID: 22841259.

17. Bai Y, Muqier, Murakami H, Iwasa M, Sumi S, Yamada Y, Ushikoshi H, Aoyama T, Nishigaki K, Takemura G, Uno B, Minatoguchi S. Cilostazol protects the heart against ischaemia reperfusion injury in a rabbit model of myocardial infarction: focus on adenosine, nitric oxide and mitochondrial ATP-sensitive potassium channels. Clin Exp Pharmacol Physiol. 2011 Oct;38(10):658-65. doi: 10.1111/j.1440-1681.2011.05550.x. PubMed PMID: 21679220.

18. Liu Y, Shakur Y, Kambayashi J. Phosphodiesterases as targets for intermittent claudication. Handb Exp Pharmacol. 2011;(204):21136. doi:10.1007/978-3-642-17969-3 9. PubMed PMID: 21695642.
19. Santos MR, Celotto AC, Capellini VK, Evora PR, Piccinato CE, Joviliano EE. The protective effect of cilostazol on isolated rabbit femoral arteries under conditions of ischemia and reperfusion: the role of the nitric oxide pathway. Clinics (Sao Paulo). 2012;67(2):171-8. PubMed PMID: 22358243; PubMed Central PMCID: PMC3275114.

20. Souza Júnior SS, Moreira Neto AA, Schmidt Júnior AF, Lemos JB, Rodrigues OR. Biochemical study of the effects of cilostazol in rats subjected to acute ischemia and reperfusion of hind limbs. Acta Cir Bras. 2013 May;28(5):361-6. PubMed PMID: 23702938.

21. O'Donnell ME, Badger SA, Sharif MA, Makar RR, McEneny J, Young IS, Lee B, Soong CV. The effects of cilostazol on exerciseinduced ischaemia-reperfusion injury in patients with peripheral arterial disease. Eur J Vasc Endovasc Surg. 2009 Mar;37(3):326-35. doi: 10.1016/j.ejvs.2008.11.028. PubMed PMID: 19112032.

22. Francisco-Neto A, Silva JCCB, Fagundes DJ, Percário S, Novo NF, Juliano Y, Moreira-Neto AA. Oxidative alterations, total antioxidant status and nitric oxide study in rats submitted to ischemia and reperfusion of hind limbs. Acta Cir Bras. 2005 Mar-Apr;20(2):134-9. PubMed PMID: 15884713.

23. Choi JM, Shin HK, Kim KY, Lee JH, Hong KW. Neuroprotective effect of cilostazol against focal cerebral ischemia via antiapoptotic action in rats. J Pharmacol Exp Ther. 2002 Mar;300(3):787-93. PubMed PMID: 11861782.

24. Wakida K, Morimoto N, Shimazawa M, Hozumib I, Nagase H, Inuzuka T, Hara H. Cilostazol reduces ischemic brain damage partly by inducing metallothionein-1 and -2. Brain Res. 2006 Oct;1116(1):187-93. PubMed PMID: 16952340.

25. Fukusawa $M$, Nishida $H$, Sato $T$, Miyazaki $M$, Nakaya $H$. 6-[4-(1-Cyclohexyl tetrazol-5-yl)butoxy]-3,4-dihydro-2-(1H) quinolinone (cilostazol), a phosphodiesterase type 3 inhibitor, reduces infarct size via activation of mitochondrial $\mathrm{Ca} 2+$-activated $\mathrm{K}+$ channels in rabbit hearts. J Pharmacol Exp Ther. 2008 Jul;326(1):100-4. doi: 10.1124/jpet.108.136218. PubMed PMID: 18381926.

26. Lee JH, Park SY, Shin YW, Hong KW, Kim CD, Sung SM, Kim KY, Lee WS. Neuroprotection by cilostazol, a phosphodiesterase type 3 inhibitor against apoptotic white matter changes in rat after chronic cerebral hypoperfusion. Brain Res. 2006 Apr;1082(1):18291. PubMed PMID: 16516167.

27. Francischetti I, Maffei FHA, Bitu-Moreno J, Fuhrmann Neto M, Coelho MPV, Kai FHT, Sequeira JL, Yoshida WB. Ação do ácido trissódio-cálcio-dietileno-triaminopentaacético (CaNa3DTPA) nas lesões de isquemia-reperfusão em membro posterior de rato. Acta Cir Bras. 2002 Out; 17(5):332-41.

28. Moreira Neto AA, Souza Júnior SS, Capelozzi VL, Parra-Cuentas ER, Schmidt Júnior AF, Francisco Neto A, Rodrigues OR. Effects of cilostazol in kidney and skeletal striated muscle of Wistar rats submitted to acute ischemia and reperfusion of hind limbs. Acta Cir Bras. 2012 Nov;27(11):783-8. PubMed PMID: 23117610.

\section{Correspondence}

Edna Frasson de Souza Montero

Alameda Espada, 134 - Res. Onze - Alphaville

CEP 06540-395 - Santana de Parnaíba - São Paulo - Brazil

edna.montero@gmail.com

${ }^{1}$ Research performed at Surgical Technique Laboratory, Department of Surgery, Federal University of São Paulo, São Paulo, Brazil. 